\title{
Status and monitoring of the buff-tailed bumblebee Bombus terrestris Linnaeus (Hymenoptera: Apidae) in Southern Finland
}

\author{
Salla-Riikka Vesterlund, Maria Kakko, Anti Vasemägi \& Jouni Sorvari
}

Vesterlund, S.-R., Kakko, M., Vasemägi, A. \& Sorvari, J. 2014: Status and monitoring of the buff-tailed bumblebee Bombus terrestris Linnaeus (Hymenoptera: Apidae) in Southern Finland. — Entomol. Fennica 25: 49-56.

Bombus terrestris can cause pollination disturbance in native plants and compete with native bumblebees and other pollinators. The accompanying non-native parasites may also threaten native bees. We report new observations of the commercially used Bombus terrestris (Linnaeus, 1758) using trapping data and sporadic samples identified with a PCR-RFLP-method for degraded DNA. A total of 863 individuals (355 queens, 442 workers, 66 drones) of Bombus sensu stricto were collected during the years 2008-9, of which, 642 were $B$. lucorum, ten $B$. cryptarum, four $B$. terrestris and none were $B$. magnus. Three trap types were compared in two modified transects near areas that use the commercial $B$. terrestris for pollination in Southern Finland: the tree trap that was hung at approximately 3 metres height was the most effective. Regular monitoring is important in the risk assessment of $B$. terrestris, and for correct species identification, molecular methods are recommended.

S.-R. Vesterlund \& M. Kakko, Department of Biology, Section of Ecology, FI20014 University of Turku, Finland; Corresponding author's e-mail: srkbos@utu.fi

A. Vasemägi, 1) Department of Aquaculture, Estonian University of Life Sciences, Tartu, Estonia; 2) Department of Biology, Division of Genetics and Physiology, FI-20014 University of Turku, Finland

J. Sorvari, Department of Biology, Section of Ecology, FI-20014 University of Turku, Finland. Present address: Department of Environmental Science, University of Eastern Finland, P.O. Box 1627, FI-70211 Kuopio, Finland

Received 14 November 2013, accepted 14 January 2014

\section{Introduction}

A non-native bumblebee to Finland, Bombus terrestris Linnaeus (Hymenoptera: Apidae), is widely used around the world in greenhouses and in outdoor gardens to pollinate for example, tomatoes and apples. In Finland, this bumblebee was introduced in the late 1980's in greenhouses and since mid 1990's in orchards. In the Southern hemisphere (New Zealand, Australia, the island of Tasmania), where there were originally no bumblebees at all, the introduced $B$. terrestris has succeeded to establish colonies and to reproduce, and has become naturalized in the wild (Semmens et al. 1993, Hingston \& McQuillan 1998, 1999, Hergstrom et al. 2002, Hingston et 
al. 2002, Goulson \& Hanley 2004). In countries such as Japan and Chile, which have their own unique native bumblebee fauna, $B$. terrestris has become the dominant bumblebee species in some areas after its introduction (Matsumura et al. 2004).

In greenhouse experiments, the presence of $B$. terrestris causes pollination disturbance in native plants (Kenta et al. 2007). Strong indications of competition between the invasive and native bumblebee species, and also between other pollinators such as solitary bees, have been reported (Hingston \& McQuillan 1999, Inoue \& Yokoyama 2006). Commercial populations of B. terrestris can be highly competitive foragers in areas with native $B$. terrestris populations, and this could even lead to the displacement of the local native bees (Ings et al. 2005). Native bumblebees can also be threatened by non-native parasites that the imported bumblebees carry, regardless of the bumblebee species in question (Goka et al. 2001).

The survival of new queens residing in commercial colonies and their hibernation outside their range in the wild remains uncertain. Agricultural producers and governmental authorities claim that the colonies, which develop outside their native bumblebee season, would suffer from adverse climatic and foraging conditions (Velthuis \& van Doorn 2006) but this issue demands more investigation. Bombus terrestris seems to be quite flexible in terms of weather and the time of year: in urban Britain, both queens and workers are active throughout the winter, which suggests a second generation during the winter months (Stelzer et al. 2010). The earlier assumption led to the free import of non-native bumblebee species in most European countries. Contrary to this policy, Norway has continued the ban of $B$. terrestris import and use based on a recent risk assessment report (Gjershaug \& Ødegaard 2012). Since 2013 in Finland, the control of bumblebee import has been assigned to Finnish Food Safety Authority, Evira, but the ecological impacts or the occurrence of this highly invasive species remain unknown.

According to various climate models the Earth's mean surface temperature will increase by $2.4-5.4^{\circ} \mathrm{C}$ between the years 2000 and 2100 (Miller 2007). The latest IPCC report predicts that the mean global temperature may rise as much as $4.8^{\circ} \mathrm{C}$ during the next 100 years (IPCC 2013). Climate change has already caused negative impacts on ecosystems in Europe, and a great majority of species will have difficulty adapting to global warming and its consequences (IPCC 2013). Furthermore, some mountainous areas in Europe are in danger of losing up to 60 percent of their natural species by 2080 if the emissions of greenhouse gases remain high (Miller 2007). Climate scenarios suggest that the increase in Finland will be approximately 3 to $7^{\circ} \mathrm{C}$ and that especially winter temperatures will increase the most, typically 5 to $7^{\circ} \mathrm{C}$ (Karttunen et al. 2008).

The first B. terrestris was found in year 1993 from Southern Finland (Pekkarinen \& Kaarnama 1994). This study reports new observations using transect line trapping data and some sporadic samples that were identified using a modified polymerase chain reaction - restriction fragment length polymorphism (PCR-RFLP)-method for degraded DNA (Vesterlund et al. 2014). Appropriate trapping methods for monitoring $B$. terrestris are also discussed.

\section{Materials and methods}

\subsection{Study area}

To study the status of $B$. terrestris in Southern Finland, bumblebees were collected during two consecutive summers (2008 and 2009) on the island of Kemiö, the largest marine island in Finland, excluding Åland. This area was chosen because its latitudinal location corresponds with the Swedish distribution of $B$. terrestris and also because this species is used both in greenhouses for the pollination of tomatoes and in apple orchards located at different parts of the island. The imported bumblebees are held outside in the apple orchards, with no control for their dispersal, from the early spring until the nests become deserted in the fall. Furthermore, the tomato greenhouses in the area are open systems, functioning to allow regular visits to neighbouring flower fields and enable the escape of both males and new queens. Because new colonies are continuously brought in from early February to late November and old ones are removed outside from the greenhouses 

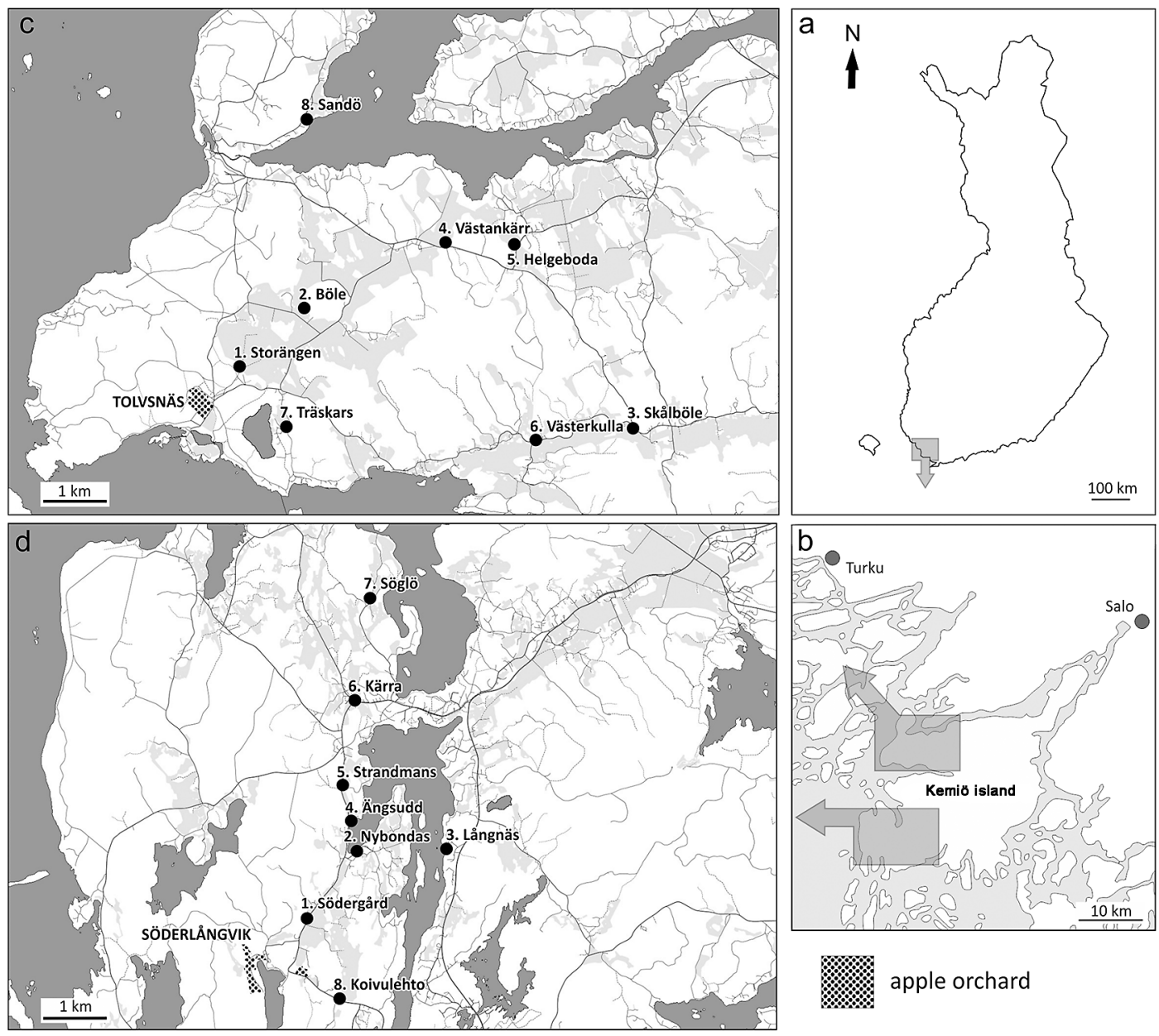

Fig. 1. Bumblebee trapping areas and transect lines in Kemiönsaari. - a. Location of the study areas in Finland. - b. Location of Kemiö island in South-Western Finland. - c. Transect line in Tölvsnäs. - d. Transect line in Söderlångvik.

when they become less active, it is possible that new queens are produced and they are able to flee and find mates. If warmer winters make also the hibernation of queens more probable, natural colonies of $B$. terrestris may be established in this area.

\subsection{Transect line trapping}

Two transect lines were established in Kemiö around locations where commercial bumblebees were used (Fig. 1). At the time of the trapping, Biobest (Belgium) commercial nests were used in the largest greenhouses of the study area. In some of the smaller greenhouses nearby, also Beeline nests (Syngenta Bioline Ltd., Holland) were used.

The first 16 traps were located around a 12 ha apple orchard with 7,700 trees in Tolvsnäs (ETRS89: $60^{\circ} 10.21^{\prime} \mathrm{N}, 22^{\circ} 27.835^{\prime} \mathrm{E}$ ) situated at a 1 to $6 \mathrm{~km}$ distance from the centre of the orchard, where the imported bumblebee nests were held (Fig. 1c). The second trapping area with 16 traps was approximately $15 \mathrm{~km}$ south from the first one, around an 11 ha apple orchard with 5,500 trees and a large tomato greenhouse of Söderlångvik manor $\left(60^{\circ} 2.077^{\prime} \mathrm{N}, 2^{\circ} 25.734^{\prime} \mathrm{E}\right)$. Along this transect line, the traps were situated at a 1 to $6 \mathrm{~km}$ distance from the greenhouse (Fig. 1d). The transect lines were modified to follow assumed main flight routes of bumblebees in 


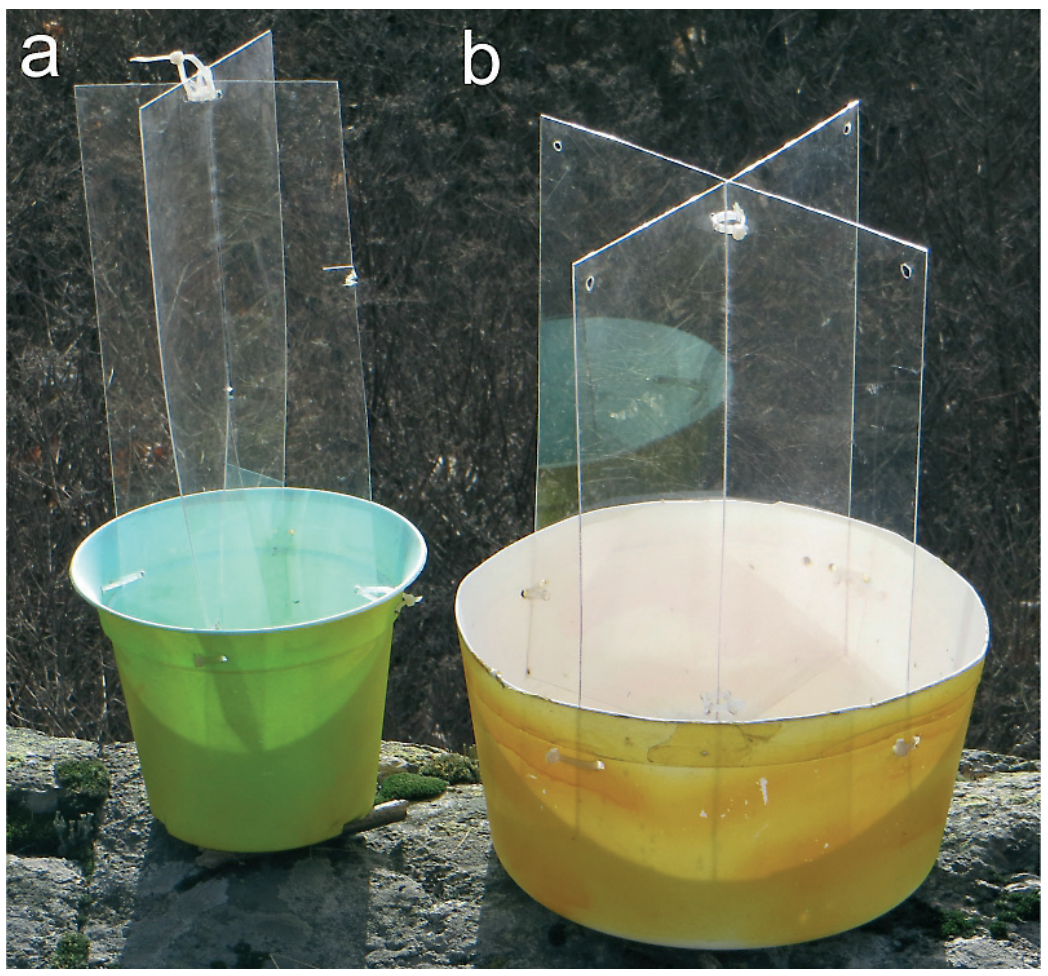

Fig. 2. Luring yellow traps. - a. Tree trap. -b. Crown trap.

those specific terrains. The main direction of dispersal was expected to be to the north or northeast in both places due to the presence of the sea in the east and south of these areas (Fig. 1).

Along both transects, 8 luring window traps were placed on the ground and 8 were hung in trees in July 2008. The ground traps were yellow plastic oblong flower planters filled with 3 litres of water, salt and detergent mixture, over which a transparent plexi glass with an area of $40 \mathrm{~cm} \times 40$ $\mathrm{cm}$ (trapping surface area $0.32 \mathrm{~m}^{2}$ ) was suspended using wooden poles. This trap type was otherwise similar to the commonly used window traps but the flower planter was painted yellow to lure bumblebees. The tree traps had two plexi glasses of size $22 \mathrm{~cm} \times 29 \mathrm{~cm}$ arranged as a cross such that insects flying toward the trap from all points of the compass would be trapped (trapping surface area $0.26 \mathrm{~m}^{2}$; Fig. 2a). The cross window was situated in a yellow round planter filled with 2 litres of the trapping liquid. The bumblebees were collected from the traps at 7 to 14 day intervals between July and August 2008.

In the spring of 2009, a third trap was hung higher in the treetops and bumblebees were col- lected between June and August. The third trap type was called the crown trap, and it was otherwise similar to the tree trap but smaller (1 litre trapping liquid, two plexi glasses of size $13 \mathrm{~cm} \times$ $24 \mathrm{~cm}$ arranged as a cross, trapping surface area: $0.1248 \mathrm{~m}^{2}$; Fig. 2b) and hung at 5 metres height in the same tree. In 2009, the trapping was started earlier in all 16 sites, before the hibernated queens started to fly and seek nest sites, as we wanted to assess the possibility of successful $B$. terrestris hibernation in nature.

\subsection{Species identification}

The bumblebees caught in the traps were first identified using morphological characters. The individuals belonging to the cryptic subgenus Bombus sensu stricto (B. terrestris, B. lucorum, B. cryptarum, and B. magnus) were later identified to species using a modified PCR-RFLP- method for degraded DNA(Vesterlund et al. 2014).

\subsection{Statistical methods}

Differences in trapping efficiency between the 
Fig. 3. Mean number of Bombus s. str. individuals collected by the three trap types (back-transformed estimated marginal means, 95\% CLs). In each location, there was one trap of each type. There is a significant difference among trap types with different letters above the CL bars (Tukey's test).

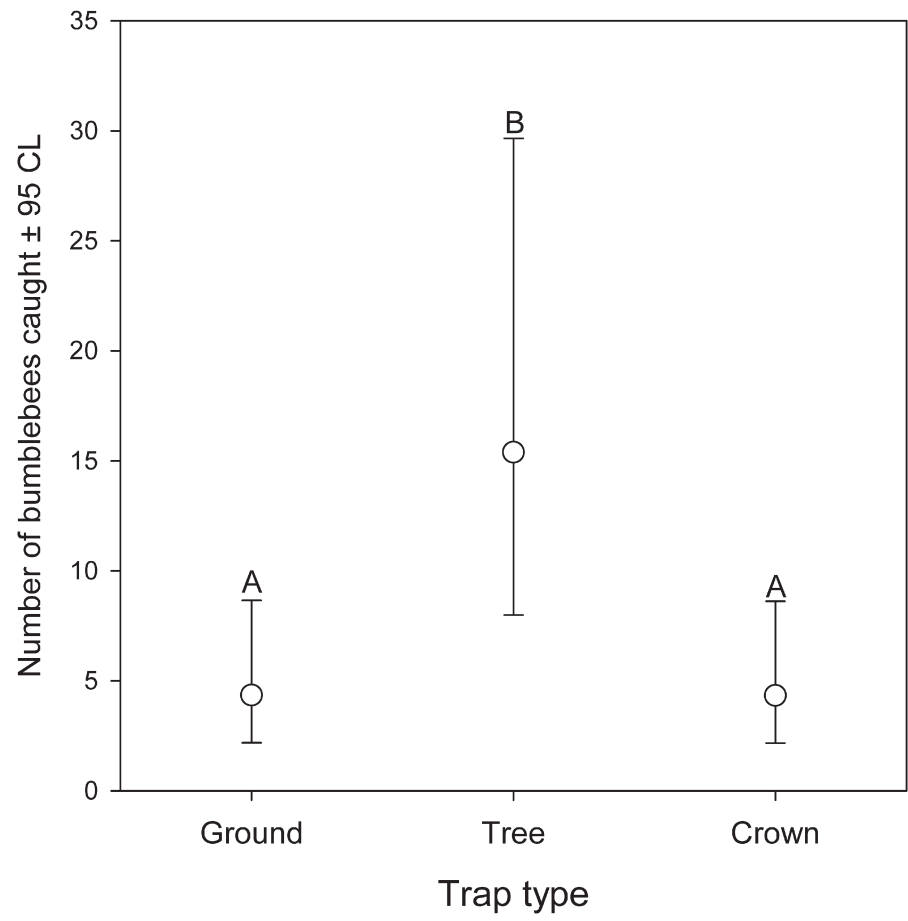

yellow traps at different heights (ground, tree and crown) were analysed using the statistical software SAS, version 9.2 (SAS Institute, Cary, NC, USA). A generalised linear model (GLIMMIX procedure) was used with negative binomial distribution and log link function. Because three different types of traps were set in the same location, the location was used as a random factor with a Kenward-Roger approximation method for the degrees of freedom. Multiple comparisons were done using Tukey's test.

\section{Results}

There was a significant difference in Bombus $s$. str. trapping efficiency among the three trap types $\left(F_{2,28.59}=12.28, p<0.0001\right)$. The most efficient trap was the tree trap, whereas the ground and crown traps were not statistically different in trapping efficiency (Tukey's test: Tree vs. Ground: $p$ $=0.0007$; Tree vs. Crown: $p=0.0007$; Crown vs. Ground: $p=0.99$; Fig. 3). The trapping surface area of the trap types did not affect the differences in trapping efficiency $\left(F_{1,32.52}=1.45, p=0.24\right)$.

Since the trapping surface area was different between the trap heights but constant within each height, the trapping surface could not be used as a covariate in the same model as trapping height. Therefore, they were used in separate maximum likelihood based models and the models were compared using Akaike's Information Criteria (AIC) values of the models (Akaike 1974). The trapping height model explained more of the variation between the traps than trapping surface model (smaller AIC value indicates a stronger model, trap height model: $\mathrm{AIC}=301.31$; trapping surface area model: $\mathrm{AIC}=316.75$ ).

A total of 863 individuals of different castes (355 queens, 442 workers, 66 drones) of Bombus s. str. bumblebees were collected with the yellow window traps during 2008 and 2009. Out of these, the molecular identification process was successful for 646 individuals. Only four $B$. terrestris individuals were found: in the summer of 2008, one worker was caught at the Tolvsnäs transect line (5.4 km from the orchard); in the spring 2009, one queen was caught in a trap five kilometres from the orchard at the same transect line, and two queens were caught at Söderlångvik transect line $6.1 \mathrm{~km}$ from the orchard. Because there were only four events (B. terrestris individ- 
uals) out of 646 trials (all Bombus s. str. bumblebee individuals), a statistical analysis was not conducted for the effect of distance to orchards on the number of $B$. terrestris individuals.

According to the initial morphological identification, we identified 60 individuals as $B$. terrestris but the verification using the modified PCR-RFLP-method for degraded DNA (Vesterlund et al. 2014) revealed that 56 of these individuals actually belonged to the $B$. lucorum complex (i.e., B. lucorum, B. cryptarum, B. magnus). Two verified $B$. terrestris individuals were initially correctly identified using morphological characters; the other two were identified first as members of the B. lucorum complex. Of the 646 individuals belonging to the $B$. lucorum complex identified based on the PCR-RFLP-approach, only 586 were correctly identified (to the complex level) using their morphological characters. The difference between the morphological and genetic identification was significant $\left(\chi^{2}\right.$-test: $\chi^{2}$ $=51.55, p<0.0001)$. This showed that the analysis of morphological characters did not result in a satisfactory identification of species within Bombus s. str. Among the collected and genetically verified samples of the $B$. lucorum complex, ten $B$. cryptarum individuals were identified while no $B$. magnus were found.

Additional $B$. terrestris samples collected by hand or as side catches during insect trapping from various locations in Southern Finland were provided by a local bumblebee breeder, Erkki Kaarnama (Forestum Oy) and Anssi Teräs (Åbo Akademi University, Turku, Finland). These samples consisted of 23 individuals ( 10 workers, 2 drones and 11 queens; Table 1). The PCRRFLP-method confirmed $B$. terrestris species identification for all 23 samples; 21 were additionally verified by sequencing a $446 \mathrm{bp}$ fragment (Sanger sequencing, Macrogen Inc., Republic of Korea).

\section{Discussion}

Our study identified a very low number of $B$. terrestris in the vicinity of the commercial orchards and greenhouses in Kemiönsaari. Only four $B$. terrestris individuals were found during the years 2008 and 2009. Based on these observa-
Table 1. Locations, numbers of individuals and collection dates of Bombus terrestris samples collected by hand or as side catches during insect trapping in Southern Finland. 21 individuals were verified by sequencing and 2 by the PCR-RFLP-approach.

\begin{tabular}{|c|c|c|}
\hline \multicolumn{3}{|l|}{ Drones } \\
\hline Haaga, Helsinki & 1 & 9.IX.2009 \\
\hline Töölö, Helsinki & 1 & 2.IX.2009 \\
\hline \multicolumn{3}{|l|}{ Queens } \\
\hline Muurala, Espoo & 1 & 5.IX.2009 \\
\hline Kauklahti, Espoo & 2 & 28.IV.2009 \\
\hline Töölö, Helsinki & 2 & 2.IX.2009 \\
\hline Tattariharju, Helsinki & 1 & 19.V.2009 \\
\hline Eestinmäki, Porvoo & 1 & 12.V.2009 \\
\hline Houtskär, Finland & 1 & 2010 \\
\hline Parainen, Finland & 1 & 2010 \\
\hline Yliopistonmäki, Turku & 1 & 27.VIII.2011 \\
\hline Yliopistonmäki, Turku & 1 & 19.VIII.2011 \\
\hline \multicolumn{3}{|l|}{ Workers } \\
\hline Haaga, Helsinki & 1 & 9.IX.2009 \\
\hline Eestinmäki, Porvoo & 1 & 12.V.2009 \\
\hline Muurala, Espoo & 1 & 5.IX.2009 \\
\hline Kauklahti, Espoo & 3 & 2009 \\
\hline Töölö, Helsinki & 2 & 2.IX.2009 \\
\hline Tattariharju, Helsinki & 1 & 19.V.2009 \\
\hline Parainen, Finland & 1 & 2010 \\
\hline
\end{tabular}

tions, we can conclude that the small-scale commercial bumblebee pollination in Kemiönsaari has not increased the number of $B$. terrestris considerably.

Novel parasites and pathogens such as Crithidia bombi Lipa and Triggiani (Kinetoplastea: Trypanosomatidae) are dispersed through the commercial B. terrestris (Otterstatter \& Thomson 2008). Even a low number of individuals can have an effect on local bumblebee populations: after an initial $C$. bombi spillover infecting approximately 20 percent of bumblebees at a two kilometres radius from the source within the first three months, the disease can form very suddenly and infect up to 35 to 100 percent of the wild Bombus, travelling forward at a rate of two kilometres per week (Otterstatter \& Thomson 2008). The outbreak of an effective pathogen from a commercial colony could have serious consequences in the Finnish native bee fauna.

In Finland, increases in winter temperatures and a prolonged growing season will benefit the imported $B$. terrestris and enhance its possibilities to spread into the wild because it is a species 
of a southern origin and is adapted to a warmer climate than most Finnish native bumblebees. On the contrary, many bumblebee species that naturally occur in Finland are cold-adapted and would most likely suffer from warmer winters and retreat north and to higher altitudes. It is therefore likely that given enough time, $B$. terrestris will become established in the southern parts of Finland, but it remains to be seen if the dispersal will be due to natural or anthropogenic routes, or both.

The number of randomly caught individuals from other parts of Southern Finland may indicate that there is more commercial pollination in these areas or that $B$. terrestris has become more common since 1994 (Pekkarinen \& Kaarnama 1994). The four $B$. terrestris queens ( 2 from Turku, 1 from Espoo, 1 from Helsinki) captured late in the summer must have either originated from natural nests or of commercial colonies. If the queens originate from commercial strains, it means that sexuals, which have dispersed from imported colonies, have been produced. Bumblebee queens from various species are able to disperse long distances after their emergence from hibernation and this migration occurs in Finland in May and June every year (Mikkola 1978, 1984, Vepsäläinen \& Savolainen 2000, Lepais et al. 2010). Thus, without a thorough DNA-based population level analysis, it is impossible to tell where the queens originate from. Bombus pascuorum queens are able to disperse at least three kilometres and $B$. lapidarius over five kilometres from their natal nest (Lepais et al. 2010). The dispersal of $B$. terrestris queens has not been well studied yet, but the drones of $B$. terrestris have been found from 2.6 to 9.9 kilometres from their birth place (Kraus et al. 2009). Thus, B. terrestris individuals caught in Kemiönsaari may have come from commercial colonies at both locations, but they might as well have been dispersed from other colonies, commercial or natural.

In Finland's National Strategy on Invasive Alien Species (2012), B. terrestris is placed in the category: "to be monitored or locally harmful." However, the distribution of $B$. terrestris is mostly unknown in Finland, but it is used as an imported pollinator in most of the tomato greenhouses, at fruit orchards, and to increase blueberry pollination. The monitoring of this species would thus be highly important for risk assess- ment. We used three different trap types, and the tree trap hung at approximately three metres height was the most effective in capturing Bombus s. str. bumblebees. The traps should not be used for regular monitoring during the spring migration and nest seeking period of queens in May and June, but the most effective time for catching workers would be late June and early August. The traps should be emptied every week if high quality DNA samples are to be acquired. The identification using morphological characters can be challenging because the colour characteristics are often blurred due to the trapping liquid and rather the highly variable genital characteristics have often to be used (Pekkarinen \& Kaarnama 1994). The identification of workers should be done using either sequencing or the PCR-RFLP-techniques developed for Bombus s. str. bumblebees (Murray et al. 2008, Vesterlund et al. 2014). As long as no data on the natural occurrence and nesting of $B$. terrestris in Finland exists, the precautionary principle in the international environmental law of the European Union should be used and all found individuals assumed being of commercial origin until otherwise proven.

Acknowledgements. We would like to thank Erkki Kaarnama and Anssi Teräs for providing additional B. terrestris samples, Lauri Rantanen for assisting in the identification process, and Tero Klemola for help in statistics. We would also like to thank two anonymous reviewers for their constructive comments that improved our manuscript. The study was financially supported by Maj and Tor Nessling Foundation (S.-R.V.), Kone Foundation, Emil Aaltonen Foundation (J.S.) and Academy of Finland project number 2608028111 (A.V.). Robert M. Badeau, Ph.D., of Aura Professional English Consulting, Ltd. (www.auraenglish. com), performed the language content editing of this manuscript.

\section{References}

Akaike, H. 1974: Anew look at the statistical model identification. - IEEE Transactions on Automatic Control 19: 716-723.

Finland's National Strategy on Invasive Alien Species 2012. - Ministry of Agriculture and Forestry in Finland. http://www.mmm.fi/en/index/frontpage/natural resources/invasive_alien_species.html

Gjershaug, J. O. \& Ødegaard, F. 2012: Vurdering av risiko for biologisk mangfold ved innførsel av mørk jord- 
humle Bombus terrestris til Norge. - NINA Rapport 895, 42 p. [In Norwegian.]

Goka, K., Okabe, K., Yoneda, M. \& Niwa, S. 2001: Bumblebee commercialization will cause worldwide migration of parasitic mites. - Molecular Ecology 10: 2095-2099.

Goulson, D. \& Hanley, M. E. 2004: Distribution and forage use of exotic bumblebees in South Island, New Zealand. - New Zealand Journal of Ecology 28: 225232.

Hergstrom, K., Buttermore, R., Seeman, O. \& McCorkell, B. 2002: Environmental research on the impact of bumblebees in Australia and facilitation of national communication for/against further introductions. Horticulture Australia project No: VG99033, The Tasmanian Museum and Art Gallery. 2002 pp.

Hingston, A. B. \& McQuillan, P. B. 1998: Does the recently introduced bumblebee Bombus terrestris (Apidae) threaten Australian ecosystems? - Australian Journal of Ecology 23: 539-549.

Hingston, A. B. \& McQuillan, P. B. 1999: Displacement of Tasmanian native megachilid bees by the recently introduced bumblebee Bombus terrestris (Linnaeus, 1758) (Hymenoptera: Apidae). — Australian Journal of Zoology 47: 59-65.

Hingston, A. B., Marsden-Smedley, J., Driscoll, D. A., Corbett, S., Fenton, J., Anderson, R., Plowman, C., Mowling, F., Jenkin, M., Matsui, K., Bonham, K. J., Ilowski, M., McQuillan, P. B., Yaxley, B., Reid, T., Storey, D., Poole, L., Mallick, S. A., Fitzgerald, N., Kirkpatrick, J. B., Febey, J., Harwood, A. G., Michaels, K. F., Russell, M. J., Black, B. G., Emmerson, L., Visoiu, M., Morgan, J., Breen, S., Gates, S., Bantich, M. N. \& Desmarchelier, J. M. 2002: Extent of invasion of Tasmanian native vegetation by the exotic bumblebee Bombus terrestris (Apoidea:Apidae). - Austral Ecology 27: 162-172.

Ings, T. C., Schikora, J. \& Chittka, L. 2005: Bumblebees, humble pollinators or assiduous invaders? A population comparison of foraging performance in Bombus terrestris. - Oecologia 144: 508-516.

Inoue, M. N. \& Yokoyama, J. 2006: Morphological variation in relation to flower use in bumblebees. - Entomological Science 9: 147-159.

IPCC 2013: Climate Change (2013): The Physical Science Basis. [www document]. URL http://www.ipcc.ch/report/ar5/wg1/ð.UkwOoKyAmrA (site visited on 14 Oct, 2013)

Karttunen, H., Koistinen, J., Saltikoff, E. \& Manner, O. 2008: Ilmakehä, sää ja ilmasto. — Ursan julkaisuja 107. Otava, Keuruu, Finland. 505 pp.

Kenta, T., Inari, N., Nagamitsu, T., Goka, K. \& Hiura, T. 2007: Commercialized European bumblebee can cause pollination disturbance: An experiment on seven native plant species in Japan. - Biological Conservation 134: 298-309.
Kraus, F. B., Wolf, S. \& Moritz, R. F. A. 2009: Male flight distance and population substructure in the bumblebee Bombus terrestris. - Journal of Animal Ecology 78: 247-252.

Lepais, O., Darvill, B., O Connor, S., Osborne, J. L., Sanderson, R. A., Cussans, J., Goffe, L. \& Goulson, D. 2010: Estimation of bumblebee queen dispersal distances using sibship reconstruction method. - Molecular Ecology 19: 819-831.

Matsumura, C., Yokoyama, J. \& Washitani, I. 2004: Invasion status and potential ecological impacts of an invasive alien bumblebee, Bombus terrestris L. (Hymenoptera: Apidae) naturalized in Southern Hokkaido, Japan. - Global Environmental Research 8: 51-66.

Mikkola, K. 1978: Spring migrations of wasps and bumble bees on the southern coast of Finland (Hymenoptera, Vespidae and Apidae). - Annales Entomologici Fennici 44: 10-26.

Mikkola, K. 1984: Migration of wasp and bumble bee queens across the Gulf of Finland (Hymenoptera: Vespidae and Apidae). — Notulae Entomologicae 64: 125-128.

Miller, G. T. Jr, 2007: Living in the environment. — Thomson Learning Inc., Canada. 784 pp.

Murray, T. E., Fitzpatrick, Ú., Brown, M. J. F. \& Paxton, R. J. 2008: Cryptic species diversity in a widespread bumble bee complex revealed using mitochondrial DNA RFLPs. - Conservation Genetics 9: 653-666.

Otterstatter, M. A. \& Thomson, J. D. 2008: Does pathogen spillover from commercially reared bumble bees threaten wild pollinators? PLoS ONE 3(7): e2771. doi:10.1371/journal.pone.0002771

Pekkarinen, A. \& Kaarnama, E. 1994: Bombus terrestris auct. new to Finland (Hymenoptera, Apidae). - Sahlbergia 1: 11-13.

Semmens, T. D., Turner, E. \& Buttermore, R. 1993: Bombus terrestris (L.) (Hymenoptera: Apidae) now established in Tasmania. - Australian Journal of Entomology 32: 346.

Stelzer, R. J., Chittka, L., Carlton, M., Ings, T. C. 2010: Winter active bumblebees (Bombus terrestris) achieve high foraging rates in urban Britain. - PLoS ONE 5(3): e9559. doi:10.1371/journal.pone.0009559

Velthuis, H. H. V. \& van Doorn, A. 2005: A century of advances in bumblebee domestication and economic and environmental aspects of its commercialization for pollination. -Apidologie 37: 421-451.

Vepsäläinen, K. \& Savolainen, R. 2000: Are spring mass migrations of bumblebees and wasps driven by vole cyclicity? - Oikos 91(2): 401-404.

Vesterlund, S.-R., Sorvari, J. \& Vasemägi, A. 2014: Molecular identification of cryptic bumblebee species from degraded samples using PCR-RFLP approach. Molecular Ecology Resources 14: 122-126. doi: 10.1111/1755-0998.12168 